\title{
Lunch Bucket D\&I: Turning Diversity and Inclusion into Competitive Advantage at UMUC Europe
}

\author{
Timothy Nerenz*, Patricia Jameson, Renaldo Walker, Bert Jarreau \\ University of Maryland Global Campus Europe, Kaiserslautern, Germany \\ Email: *timothy.nerenz@faculty.umuc.edu
}

How to cite this paper: Nerenz, T., Jameson, P., Walker, R. and Jarreau, B. (2019) Lunch Bucket D\&I: Turning Diversity and Inclusion into Competitive Advantage at UMUC Europe. Journal of Human Resource and Sustainability Studies, 7, 261-276. https://doi.org/10.4236/jhrss.2019.72016

Received: May 8, 2019

Accepted: June 18, 2019

Published: June 21, 2019

Copyright () 2019 by author(s) and Scientific Research Publishing Inc. This work is licensed under the Creative Commons Attribution International License (CC BY 4.0).

http://creativecommons.org/licenses/by/4.0/

\begin{abstract}
All post-secondary institutions proclaim a commitment to diversity and inclusion (D\&I); it is precisely the universality of these pronouncements that disqualify them as a source of competitive advantage as the term is properly understood-something valuable, rare, inimitable, and non-substitutable. This paper describes a more expansive approach to diversity and inclusion undertaken at University of Maryland University College Europe, which has advanced D\&I's role and contribution from providing compliance and advocacy to creation and promotion of competitive advantage, using examples from its MBA program to illustrate key concepts. Coined "lunch-bucket D\&I", the approach honors traditional D\&I initiatives and programs, but adds a supplemental focus on integration of embedded inclusive practices into the daily work of students, faculty, and staff to create a uniquely inclusive environment that attracts and retains top talent. Combined with its formal D\&I programs and Speak Up! initiatives, UMUC Europe's "lunch bucket D\&I" approach demonstrates the potential for D\&I to be leveraged to create true competitive advantage in post-secondary education.
\end{abstract}

\section{Keywords}

Diversity, Inclusion, Competitive Advantage, Education, Leadership, MBA

\section{Introduction}

In the Spring of 2018, Vice President and Director of University of Maryland University College Europe, Tony Cho, asked our Director of Diversity and Equity Programs, Patricia Jameson, a seemingly simple question: "How is diversity and inclusion a competitive advantage here at UMUC?" (T. Cho, personal communication, October 25, 2018). 
UMUC Europe maintains a highly-regarded formal D\&I program, and is engaged with the community with regular events, celebrations, and awareness initiatives, and has achieved exemplary diversity in its student, staff, and leadership profiles-10 of its 13 top administration incumbents are women, minorities, veterans, or people with disabilities.

But program quality was not the question. The question concerned competitive advantage, and specifically, how (if) D\&I has contributed to it. It is a CEO's question, not an academic's rumination. So when Ms. Jameson brought the question to our Diversity Council for discussion, it was its three MBA professor members who immediately recognized the necessary focus of the response. With combined decades of experience in industry and teaching in other institutions, we noticed the enhanced educational experience provided by the uniqueness and diversity of our classroom, faculty, and course design from the first days of our appointments.

The council discussions on the competitive advantage question developed an expanded notion of D\&I to include what has been labeled "lunch-bucket D\&I", a deeper level of diversity and inclusion so engrained into our daily work and teaching at UMUC Europe that it is no longer remarkable and often unconscious. It is the premise that diversity matters most after we return from the training sessions, lunch-n-learns, group photos, and celebrations, hence the monicker "lunch bucket". It is recognizing and harnessing the power of the richer diversity of perspective, experience, opinion, communication style, personality, intellect, EQ, family experience, outside interests, and talent that each individual brings to the workplace; tapping into that diversity is what turns good ideas into great ones and provides UMUC with a competitive advantage in attracting and retaining students, staff, and faculty.

This paper will describe the lunch-bucket D\&I concept as it is put into practice at UMUC Europe, with a focus on its most prominent example-the MBA program, where imbedded inclusive practices have supplemented the foundation of traditional D\&I program initiatives and the university's Speak Up! initiative to create a distinct and measurable competitive advantage.

The process of preparing that briefing for the VP and Director was itself a case study in walking the talk of lunch-bucket D\&I. Ms. Jameson instinctively sought input from a diverse group of perspectives, a willing business faculty spoke up, and a volunteer committee of faculty, staff, and administration engaged in penetrating self-examination of both traditional and unorthodox notions of diversity and inclusion that turned a good idea into a great one. It not only answered one post-secondary leader's question but provided some ideas for others who seek to move their own stalled D\&I initiatives from compliance to competitive advantage.

\section{Lunch-Bucket D\&I Defined}

Most people think of diversity and inclusion (D\&I) in terms of celebratory pro- 
grams and anti-discrimination compliance procedures and training, along with advocacy for underrepresented communities and cultures through educational awareness events. We mark certain months, weeks and days on our calendars to raise awareness and celebrate statutory diversity-group identities codified into laws and regulations. We develop compliance policies aimed at eradication of harassment, discrimination, violence, and exclusion in the workplace based on race, ethnicity, age, gender, sex, religion, physical ability, veteran status, and sexual orientation. And we promote inclusiveness through messaging, imaging, symbols, and leadership communications.

Most post-secondary institutions have created leadership positions with titles to convey the importance of Diversity and Equity-Dean, Director, Vice-President, for example. Most large corporations and government agencies will have similar prominent officer-rank positions to display commitment to D\&I and equity themes. Staff positions are dedicated to D\&I, advisory committees are formed, separate D\&I pages are added to websites, and we sponsor D\&I events, publish newsletters, host webinars, wear ribbons, create social media sites, and include D\&I sections in our formal management reports. Great care is taken in selection of photographs used in corporate communications to insure that all groups are represented and a welcoming image of the organization is conveyed.

D\&I has its own lexicon of preferred words and phrases, i.e. "women of color", "under-represented minorities", "welcoming environment", "safe spaces", "inclusive", "supportive", "privilege", etc., as well as a growing list of words and phrases to be avoided to limit risk of offense. A heightened sensitivity to messaging in all of its forms-written word, spoken word, pictorial, graphics, statistical presentation-is the norm in the post-secondary business model.

These traditional D\&I activities are valuable, but they are not rare, inimitable, or non-substitutable, the other three components of the VRIN criteria by which competitive advantage is defined and weighed [1].

"Lunch-bucket D\&I" is a phrase coined to capture the integration of the principles of diversity and inclusion into the daily work that we do at UMUC Europe. It is unconsciously putting the platitudes into practice-without fanfare, without celebration, without adding the outward symbols and labels and claims of virtue. It is what we do when the training is over and we go back to work. It is the notion of being inclusive on the first pass, not performing a task or developing a work product and then sending it over an isolated "diversity department" to be checked and corrected or sanitized for public consumption or compliance with an external universal standard. It does not replace tradition D\&I, it the important supplement that realizes the promise of diversity through incorporation of inclusive practice.

Lunch-bucket D\&I is something that is discovered retrospectively, rather than planned in advance; it develops organically through human interaction; there is no blueprint or recipe to be followed.

And it is recognizing a far wider range of diversity than the statutory list of 
class membership; a range that appreciates the full spectrum and dimensions of human capacity and experience, not simply a handful of easily identified characteristics. The premise of lunch-bucket D\&I is that diversity is not an end to itself; it is a means to an end, namely improved organizational performance. Inclusion is the pathway by which diversity affects performance.

Many organizations are diverse but not inclusive [2] [3]; that is, they exhibit all the trappings and symbols and present a wonderful photo at the company picnic, but on a daily basis "groupthink" - the tendency to apply a very narrow set of perspectives when assessing a new situation or generating solutions to an emerging problem-is the order of the day. It is no accident that the notion of lunch-bucket D\&I at UMUC Europe would evolve from the business school faculty-groupthink has been a major cause of business fatality and avoidance of groupthink has been a focus of scholars and practitioners for more than half a century [4].

UMUC Europe's lunch-bucket D\&I expands the notion of diversity to embrace the full spectrum of variability that exists in any population-diversity of experience, intellect, humility, empathy, ego, honesty, stamina, learning style, responsibility, charity, charisma, curiosity, family structure, talent, education, IQ, EQ, self-image, definitions of effectiveness to name some of the more obvious. These are individual traits whose range is independent of group-identity assignment.

\section{What Is Competitive Advantage?}

Every MBA student learns about competitive advantage and how to recognize it, develop it, and leverage it. It is the collection of product/service attributes and core competencies that separates a firm from its competitors in the minds of a consumer. The acronym VRIN [1] has stood the test of time as the weighting standard-a particular core competency that is valuable, rare, inimitable, and non-substitutable. Proper application of the VRIN principle in the business ecosystem recognizes that the customer, not the firm, passes judgement on these characteristics. In the post-secondary model, the prospective student is the primary customer in this context.

We can determine if something represents is a true competitive advantage if customers will pay more for it, will wait for it, will buy more of it, or will recommend it to friends. "It" can be anything-our products, our services, our brands, our company image, our values, our influence, our CEO or founder's charismatic presence. But for a thing to be a true competitive advantage, it must not simply exist, but move people to act-i.e. buy it or rent it or use it.

In the application of the competitive advantage principle, employees, investors, and suppliers are also "customers". In the private sector, choice and competition remove mediocrity from market space; firm failure is the default setting and constant stream of new and better ideas is essential to the survival of the organization. Those new and better ideas come from attracting the best talent, 
from listening to customers and employees, from attracting investors and business partners so that best practices from outside the organization can be shared. Competitive advantage is fluid-expectations continuously rise and with globalization and technology, the pace of change and risk of irrelevance is heightened each year.

True competitive advantage can be observed, and it can be measured. But what is very difficult to sort out of empirical data is the relative strengths of its two components: 1) the existence of the competitive advantage itself and 2) the convincing (marketing, messaging, selling) of customers that it benefits them. If customers do not perceive value and act upon it, true competitive advantage is not established.

Post-secondary education institutions often exhibit a certain disdain for the market aspects of their existence, but universities and colleges must compete in the marketplace for students, staff, faculty, and capital (private donors or public funding). While the ethos of collegiality in the academy may seem to be in conflict with competition, the fact of the matter is that faculty, students, staff, and donations all come to an institution by choice. A competitive advantage must be established, and it must be communicated persuasively.

\section{Lunch-Bucket D\&I in the MBA at UMUC Europe}

University of Maryland University College is unique among public universities in many ways. One in particular is its long-standing commitment to serving the military community stationed overseas. Its European component (UMUC Europe) is headquartered in Kaiserslautern, Germany and offers undergraduate and graduate degrees with residential classroom instruction on military bases throughout Europe and the Middle East under a contract with the US Department of Defense. UMUC Europe students are active duty military (American and NATO), spouses, and veterans living in the area with base access privileges.

UMUC has been a leader among US public universities for many years and has been recognized with numerous citations and awards. If capital-D diversity was an end unto itself, UMUC-Europe would be a poster-child for how it's done. Of the top 13 management positions in administration, 10 are held by minority or female incumbents, including our Director, Tony Cho. Veterans are over-represented in staff and faculty (compared to national demographics) and our D\&I Director, Patricia Jameson, is recognized as a leader in her professional field. Our D\&I committee is large, diverse, inclusive, and very active. It sponsors popular events and educational outreach, and we participate with our military base communities in their D\&I initiatives consistently.

One of the unique characteristics of UMUC Europe's D\&I committee is its disproportionate number of MBA faculty; the business school does not pop immediately to mind when the term "D\&I" is heard. While MBA professors make up $10 \%$ of the faculty, we make up over half of the faculty who have volunteered to serve on the university's D\&I committee. 
The MBA program at UMUC Europe is a hybrid, with both online and face-to-face classroom components in every course. Each 6-credit course contains 48 hours of classroom time (one weekend per month) over the 11-week term. The MBA is the terminal degree in business; we deal in frameworks and concepts, not recipes. Bridging theory to practice is achieved through a combination of self-study of scholarly works, guided online discussions, classroom discussions and activities, lectures, group-work, and one-on-one mentoring and coaching.

Of keen interest to MBA faculty on the D\&I committee is expanding the notions of diversity - not replacing or altering UMUC Europe's traditional D\&I initiatives but adding a visible practice component that can be replicated with appropriate adaptation in other faculties outside of our own MBA. Our teaching and research are concurrent; our classrooms are both lecture halls and laboratories. We teach our students to be inclusive leaders by being inclusive; we bring what we learned and practiced in the private sector-where competitive advantage is a life or death matter to the firm-into our course syllabi and our classroom activities.

The evolution of the notion of lunch-bucket D\&I is in itself a case study in inclusive collaboration. Over a period of weeks several members of the D\&I committee engaged in wide-ranging exchanges that clarified and focused upon four elements of our MBA program that create the opportunity for competitive advantage: diversity in our classrooms, diversity in our faculty, diversity in our courses and pedagogical devices, the marketing of diversity in recruitment and outreach.

It is important to point up the organic ad-hoc nature of the development of these themes. There was no plan, no charter, no schedule of meetings, no particular leader or even team structure. It was, and is, a perpetual work-in-process, with ideas implemented as they become obviously needed and refinements of thinking managed by the "invisible hand" of new ideas tossed out there for discussion and consideration. Business faculty on Diversity Council were invited to a monthly meeting at orientation, we joined for the good ideas we can use to make our classroom lectures on business subjects better-it is voluntary and uncompensated time. How many post-secondary institutions have grad professors from the B-school coming on their own time to find out what' new inclusive practices are working better for undergrad admissions advisors and benefits coordinators so we can bake it into our next lectures on global finance or strategic decision-making? That's lunch-bucket D\&I.

Lunch-bucket D\&I is not a recipe that can be duplicated; it is a framework from which each faculty can develop an authentic approach to diversity and inclusion into a recognizable and sustainable competitive advantage. There is no single diverse and inclusive classroom experience in the MBA; no blueprint around which the courses are planned. There are a series of different experiences, a diversity of diversity, if you will-that is the point. 


\section{Diversity in Our Classrooms}

Nationally, MBA programs tend to draw very low minority enrollments and nearly $70 \%$ male graduates [5]. The statistics do not do justice to the reality of classroom diversity at UMUC Europe but they are nonetheless impressive; 54\% of our MBA graduates in 2018 were members of historically underrepresented minorities. My winter quarter MBA670 capstone course was a typical MBA cohort; in a class of 13 students preparing to graduate, there were only two white males; the classroom was a mix of races, genders, ethnicity, religious belief, physical ability, native language, age, and orientation. The range of age was 22 to 61. In addition to inherited traits, the cohort was unusually diverse in acquired traits-counted among them was a Medical Doctor, a lawyer, a financial fraud investigator, a contract fraud investigator, two retired Lieutenant Colonels, a retired tank commander, an engineer, a recruiter, tand wo female business owners.

One student was injured in combat three times, one had led projects with thousands of troops and nearly hundreds of millions in budgetary authority, and another had never held a job of any sort. At least three religions were represented, every skin tone on the spectrum, and combined the class had lived (6 months or more) in over a dozen countries. Introverts, extroverts, critical thinkers and emotional responders, the confident and the timid were all in one room for 48 hours of in-residence groupwork and discussion and ten weeks of online coursework.

That is rare-I have never seen anything like it in 30 previous MBA classrooms at other institutions. It is valuable-we have students who fly over here from the United States monthly to join a diverse and inclusive cohort-based program offered here. It is inimitable-competing institutions cannot access the pool of MBA candidates that produces this diversity of experience and background or provide face-to-face group interaction on military bases overseas. It is non-substitutable-a purely online option or a purely residential option would not provide the same facility for interaction while meeting the requirement for flexibility and accommodation of duty calls and deployments.

Diversity of skin color and gender makes a nice photo op, but it is inclusion drives improved performance. Drawing out the full spectrum of ideas and perceptions into critical analysis is how improved performance is achieved, whether it is on the factory floor, in a design studio, a corporate boardroom, or a university classroom. That is where faculty comes in.

\section{Diversity in the MBA Faculty}

The core MBA faculty at UMUC Europe was recruited and assembled to provide students with the wisdom and insight from a combination of scholarship and practitioner experience. All of the full-time CTF (Collegiate Traveling Faculty) hold doctoral degrees in business or economics or law, but in addition bring at least 20 years of international executive experience in the private sector.

Our faculty roster includes a former company President, former Chief Inno- 
vation Officer, former corporate lawyer, former marketing executive, and Subject Matter Expert (SME) in international finance and administration. We all hold doctoral degrees and have taught at the graduate level for many years at universities in different countries. We are both scholars and practitioners; teachers and researchers; mentors and coaches and experts in our fields. We can create engagement in our classrooms because we have done it in our businesses. We have hired MBAs, fired MBAs, promoted MBAs, demoted MBAs, and sponsored MBA degree programs for young leaders with executive potential.

Our list of scholarly publication is modest; we led firms the scholars studied. We subscribe to no particular dogma; in fact, we disagree on many things in our monthly informal salon discussions. We value our diversity of experience and belief; it is valuable, it is rare in the modern academy, it is inimitable, and it is non-substitutable. Our students will receive the combined wisdom of 150 years of inclusive executive experience in addition to sound theory and principle as they complete their MBA studies.

Studies show that companies who master diversity and inclusion outperform those who do not [6]. Our MBA faculty is drawn from the high-performing pool of firms-not because we believe in diversity as an end unto itself, but because we understand competitive advantage and have a track record of creating and sustaining it in the global economy where only the best ideas and execution can prevent the extinction of the firm.

Traditional D\&I would recognize that our teaching faculty is modestly diverse in terms of race, gender, nationality, first language, veteran status, and disability. Lunch-bucket D\&I is the deeper appreciation of the vast diversity of experience, perspective, pedagogical preference, leadership style, teaching philosophy, EQ, platform flexibility, research interest and other differentiators that provide students with a depth of learning and mentoring that can only occur in an organically diverse and inclusive environment.

Recruiting such a diverse and experienced MBA faculty was no mistake. It was a direct result of talent acquisition. Renaldo Walker, an adjunct MBA professor at UMUC Europe and UMUC HR Generalist in the Human Resources Department, describes how recruiting true diversity creates the opportunity for competitive advantage in an organization.

"I have conducted hundreds of job interviews over the course of my 15-year career in Human Resources and can undoubtedly attest to the fact that talented employees represent a unique opportunity for gaining a competitive advantage in any organization.

As both a Personnel Recruiter and Military Human Resources Liaison for the United States Air Force (USAF), I had the pleasure of interviewing anywhere between $180-250$ candidates a year over the course of approximately 7 years.

Throughout the course of these numerous interview experiences, I took advantage of the opportunity to make a mental note of the diverse demographics of the USAF. One aspect of the diverse demographics that really resonated with me was the number of personnel that I had interviewed who specialized in a field 
completely different from that of which they desired to pursue in the USAF.

It was then that I grew a greater understanding of why in the 15 years previous to my appointment in USAF Recruiting Services, that I had been witness to so many significant accomplishments attained above \& beyond the pre-defined roles of those attaining those accomplishments. They were in essence performing outside of the boundaries of their job descriptions to serve a higher cause".

Performances such as those previously mentioned, arise from the true power of talent acquisition. More notably, it is important to note that talent acquisition represents something that basic recruitment does not. Sahay's [7] study found that the process of developing talent relationships forces managers to develop a more outward-looking view, staying on top of cutting-edge trends, building their company's image and staying in sync with customer expectations. This is but the essence of the design thinking methodology-aking insights from people at the various stages, touch points of the process and build from the outside-in rather than from the inside-out.

Furthermore, talent acquisition is denoted by the recognizing and leveraging of all of the employee qualities that exists outside of his or her job description. These qualities are generally annotated in an applicant's resume or conveyed during the interview process. Sahay's [7] idea of recognizing all of the employee's qualities are key to developing a workforce capable of turning diversity and inclusion into a competitive advantage.

Just as the UMUC Europe MBA faculty were assembled to create a rich diversity of experience, perspective, and viewpoint, every staff and faculty hire is an opportunity to enrich and expand the talent pool. The hallmark of a true talent acquisition company can be found in its approach to recognizing and taking advantage of opportunities to get more than they bargained for, and then to encourage and empower employees to engage and contribute in ways that make the whole greater than the sum of its parts.

\section{Diversity in Our Courses}

The UMUC MBA curricula was extensively revised in 2016-17, with courses redesigned to support the Enhanced Learning Model (ELM) with its emphasis on competency-based learning by doing [8] Courses are built around competencies defined by industry, with learning objectives developed to support each competency cluster and projects designed to both acquire knowledge as well as demonstrate comprehension and application of theories, principles, and frameworks contained in the literature.

Projects are evaluated against rubrics and are graded via evaluation of final deliverables-papers, presentations, plans, spreadsheet analyses, statistics and quantitative analysis, memos, etc. For each project, interim milestones are established and scheduled for submission, so professors can evaluate and provide feedback (un-graded) on work in progress and develop each student's skillsets and mastery of the key ideas individually over the weeks of the course. 
While the individual courses focus on particular clusters of business leadership topics, most of the projects within them contain elements of diversity, inclusion, and/or multi-cultural awareness. The focus of the entire curriculum is on global leadership in the world economy, and the MBA students are preparing for a career in which they will be responsible for ethical and legal decision-making across many different nations, regions and cultures.

It is crucial to note that there is no "diversity" project in the MBA. The "secret sauce" of lunch-bucket D\&I is that it is a mindset that is organically imbedded into every project. For example, the capstone MBA670 course "Strategic Decision Making" assesses learning across 24 competencies across five projects. The fist is a group discussion of global CEO profiles and leadership styles. The second is a group project to develop a project plan to build and open a new big-box home improvement store in Quebec City for a fictional Maryland retail chain. The final three are a trilogy to select a multi-national company from a list provided and develop an actionable market entry proposal and business plan for expansion into a developing country in which they do not currently operate, in alliance with a local firm as a selected strategic partner.

Each of these projects requires research, critical analysis, and application of academic frameworks in scenarios that are multi-national, multi-cultural, multi-lingual, and require examination of the full spectrum of legal, ethical, cultural, moral, economic, ethnic/racial, political, social and language differences in addition to the business issues of strategy, competition, finance, marketing, organizational development, leadership, human capital, etc. This approach to course design is evident in every one of the MBA programs.

We teach by doing-in both our online self-learning and discussions and in our residential discussions and group-work. We do not hit the "pause button" on graduate studies in business to take a time out and talk about diversity, then return to real work when our required diversity chat is completed. We have embedded the notions of inclusiveness and cross-cultural awareness seamlessly into the work itself.

\section{Marketing Lunch-Bucket D\&I}

While the number of institutions offering on-site classroom instruction on US military bases in Europe is restricted, potential MBA students have the option of enrolling in off-base campuses of American universities, local universities, and online offerings from degree-granting institutions from around the world.

In March of 2018, the enrollments for the start of MBA cohorts in the Spring quarter were tracking far below the budgetary plan and a three-week promotional blitz was proposed to raise awareness of the UMUC Europe grad programs and persuade undecided potential students to enroll.

In addition to the conventional marketing and recruiting elements-web-sites, advertising, information drops, field office outreach, career counseling, financial aid assistance, etc., a new element was proposed by Patty Sanchez, Graduate and 
Partnership Student Initiatives Manager-inclusion of faculty into outreach efforts and integration of D\&I into our "elevator pitch", the key takeaway points of differentiation marketers use to create competitive advantage in the minds of potential customers.

Three MBA faculty fanned out to support operations staff cover at open-house events held on five military bases, a webinar was hosted in which diversity and inclusion was listed in the key advantages of the program and highlighted in the narrative, a Facebook live segment featured faculty discussing inclusion and engagement in the classrooms, and faculty fielded potential student's questions about the courses and activities on referral from student advisors. We took calls up until the midnight deadline for enrollment.

The focused effort was not just about diversity and inclusion, it was itself diverse, and it was inclusive-Ms. Sanchez and the MBA faculty are not responsible for enrollment numbers, so the effort was an "and" exercise, i.e. in addition to all the other work done by those who are responsible for enrollment, recruitment, and retention of students. Including faculty in the process more than tripled the number of available student resources for specific questions that would determine their choice of an MBA program during that enrollment period, and explicit promotion of our unique diversity and inclusive model opened new avenues of dialogue on student perceptions of differentiation.

While certainly not solely due to marketing lunch-bucket D\&I, adding the competitive advantage of diversity and inclusion of our cohorts, faculty, and courses into the marketing mix contributed to a significant and immediate increase in enrollment numbers-new student enrollments in the final two-week campaign were more than triple those achieved in the ten weeks prior.

The competitive advantage that lunch-bucket D\&I provides to our MBA program is not limited to making it more attractive to underrepresented minority and females. At a recent mock-classroom outreach event in Wiesbaden, Germany where our D\&I competitive advantage was highlighted, $100 \%$ of attendees were persuaded to enroll-predominately white males. The value of learning inclusive business leadership in our diverse and cross-cultural environment is universally recognized.

\section{UMUC Europe's Overseas Diversity and Equity Program}

The notion of lunch-bucket D\&I is not meant to replace the existing framework of Diversity and Equity Programs in place at UMUC Europe. On the contrary, it is the excellence of these programs that creates the environment in which authentic diversity and inclusion actions can occur naturally and regularly. Patricia Jameson is the Director of Diversity and Equity Programs at UMUC Europe and is responsible for UMUC Europe's excellent D\&I program.

The University System of Maryland (USM) strategic plan (2018) includes new 2020 goals, including "Equity, Diversity, Inclusion, and Civic Engagement: Valuing and Celebrating All Maryland Residents". The plan states, among other 
items, Long an area of focus, the USM has adopted new targets to reflect the rich diversity of its students, faculty and staff, an to ensure that all are more fully included, regardless of ability, background, gender, gender identity, race or ethnicity, creed, perspective, or national origin [9].

The mission of UMUC's Overseas Diversity and Equity Programs is to promote UMUC's (a school in the University of Maryland System) commitment to foster diverse and inclusive working and learning environments while ensuring compliance with the university's nondiscrimination policies as well as applicable state and federal laws. Priorities include: increasing awareness through multicultural programs; training, diversity council members serving as diversity advocates; active engagement and visibility through site visits, faculty meetings; athletics and outreach; and community involvement.

\section{Speak Up! - A Voice Unheard Is a Lost Opportunity for Individual and Collective Growth}

Speaking up, meaning addressing a concern with mutual respect and/or sharing perspectives and experiences, plays an instrumental role in diversity and inclusion work. It is critical for inclusiveness. Speaking up may sound more simple then it is. It is loaded with power and influence. As we all have probably experienced, words have the power to hurt or encourage/build and need to be handled with care.

Communication overall is an invaluable tool for building rapport and managing diversity. It also seems like one of the most challenging things to master. Speaking up, when handled with care, can foster inclusion and growth in a diverse environment.

Speaking up is an invaluable resource in the classroom and workplace. It allows us to learn more about why people act the way they do and can help avoid misunderstandings. Master Sergeant (MSG) Wendy Williams, 7th Mission Support Command Equal Opportunity Advisor and Non-Commissioned Officer, describes speaking up as "sharing experiences and bridging the gap while building common ground" (W. Williams, personal communication, July 26, 2018).

Challenges

Speaking up can be tricky in diverse organizations, where people have different attitudes, behaviors, and values. For some, the idea of speaking up can be unsettling as one does not know what the impact or result of speaking up will be. Some fear an unfavorable impact. The uncertainty of the outcome sometimes prevents people from speaking up.

It is important to be mindful of barriers to speaking up and to know they exist, so you can try to eliminate these when speaking up. Fear is a major barrier. Other barriers include and are not limited to personal biases, language, lack of cross-cultural awareness, insecurity, conflict in values, comfort zone, micro-aggressions, ethnocentrism, unrealistic expectations, and resistance.

These barriers can be reduced by: 
Recognizing and acknowledging barriers exist and managing them;

Helping people understand themselves, their peers, and how we can all work together in a positive way;

Open and Safe Venue for All: It is important to establish an environment where all members of the community feel "safe" to speak up. Such an environment needs to include mutual respect and protection from retaliation;

Identifying and building on common ground;

Training and active learning opportunities for application.

\section{Strengths}

To raise awareness, encourage speaking up and respectful communication and reduce barriers, we offer multicultural programs, training for faculty and staff, and engage with students on topics related to diversity, equity, civic engagement, and inclusion.

Our multicultural programs include heritage month observances aimed to celebrate diversity, grow our cross-cultural awareness/sensitivity, and foster inclusion. We have invited staff, students and faculty to share their experience and insight to make our heritage month observances more meaningful and relevant as focus is not only on the heritage being recognized but also on members of our UMUC community. Examples include and are not limited to the following observances.

For PTSD awareness month 2017, we invited two undergraduate students, veterans with Post Traumatic Stress Disorder and Traumatic Brain Injury, to share their experience and insight on how we can be more accessible and inclusive in our services and in our classrooms. Noteworthy is that both wanted to "speak up" to help raise awareness, and they felt safe enough to speak on sensitive topics with us. Consequently, the students were invited by the Europe Vice Dean to speak at a faculty meeting, which resulted in a valuable learning experience for our faculty and an opportunity for meaningful discussions with the students for mutual learning and increased understanding.

We hosted a Military Appreciation Month ceremony in May 2018. A Colonel (Ret.) of the Royal Netherlands Air Force, along with a Chief Master Sergeant and Senior Master Sergeant of the US. Air Force, both of whom are students earning their MBA degrees served as our guest speakers. Col (Ret.) shared his experience about working in a multi-national military environment while the Chief Master Sergeant and Senior Master Sergeant shared their experience in the military, to include from a student's perspective.

Our Multicultural Training and Programming provides services, information, and training support. Training is tailored to support identified needs on topics that include interpersonal and intercultural communication, multigenerational differences, managing diversity in the workplace, diversity and inclusion, conscious and unconscious bias, sexual harassment, civil treatment, among others. Sometimes the office teams up with other internal departments (i.e. Human Resources) or external (local military equal opportunity representatives and sexual 
misconduct response and prevention teams) for training and team building opportunities to diversity the learning opportunities for all stakeholders.

Our diversity council consisting of staff, students, and faculty recently presented (and spoke up to the challenge) to leadership on "Diversity Matters: The UMUC Europe Competitive Advantage". Objectives included establishing common ground (i.e. diversity and inclusion defined), signifying how diversity is a competitive advantage, demonstrating how diversity and inclusion can further leadership priorities and result in high performance, and identifying opportunities moving forward. The presentation was broken down into three perspectives-from field staff, headquarters, and MBA Program faculty.

The field spoke on how diversity matters in growing enrollments, doing what is in our students' interests, and being inclusive leaders at every level, and instilling this value in our culture. Headquarters provided a historical perspective and how UMUC always championed diversity, a newcomer's perspective on how to leverage our organization strength-its human capital, a HR perspective on how talent acquisition and management plays a vital role, and a marketing perspective on how embracing diversity and inclusion is at the heart of our brand.

Perspectives from our MBA program faculty focused on diversity of our classrooms, diversity of our faculty, diversity embedded into courses, and marketing diversity as a competitive advantage. The presentation concluded with an action plan using input from the different perspectives for opportunities moving forward.

The Director of our Overseas Diversity and Equity Programs visits our MBA cohorts to provide an overview of our Diversity and Equity Program as well as discuss relevant topics with our students for implementation. Our diversity council, consisting of staff and faculty throughout Europe and the middle east serve as diversity advocates and serve as resources in the field. Our diversity council explores strengths and opportunities.

\section{Conclusions}

The evolution of diversity and inclusion in organizations has moved over decades from tactical and operational schema designed to avoid "group-think" to removal of structural barriers that discriminated on the basis of race and gender (for instance), to affirmative measures to build more inclusive organizations, to more formalized programs of diversity and equity to organizational hierarchies that elevate D\&I priorities through delegation of authorities to officials with explicit D\&I responsibilities within the organizational form.

While these advancements have produced benefits of awareness, and compliance with statutory obligations, they can become impediments to continual progress towards full integration of inclusive practice throughout the organization's daily fulfillment of its mission if D\&I is seen as something independent and isolated from the "real work". While no organizations are abandoning diversity as a goal, many are questioning the value of D\&I programs as they cur- 
rently exist, and the D\&I community itself struggles with seemingly having hit the wall-achieved compliance and awareness, but struggling to figure out how to take the next step and turn diversity and inclusion into the competitive advantage that we all believe it could and it should deliver to our organizations. It is a topic of keen interest in post-secondary and across all industry sectors.

The paper has described a way of thinking about D\&I that offers a possible path forward-recognizing that diversity is not an end to itself but a means to an end, just as quality or safety would be considered in an industrial firm. We have traditionally focused on the means, and need to focus on the ends-what is the purpose of D\&I here, in each particular organization? What are we trying to do, and how does D\&I explicitly make us better at what we are trying to do? And just as an industrial firm would invest in quality and safety specialists and join in profession communities in those realms to access best practice and advancement in research and theory, those values do not become true competitive advantage until they are integrated and imbedded deeply into the daily work of everyone in the firm.

That is the principle borrowed from industry that carries over into "lunch bucket D\&I" at UMUC Europe and it is no surprise that it would emerge from the MBA program, where faculty was used to lead goods-producing firms during the decades when racial and gender integration was a strategic imperative that firms ignored at their peril. Like all principles, they are to be understood contextually-each circumstance requires an adaptation in application; it is why we will always need human beings to "operate the machinery" of leadership. The paper is not offered as a recipe, rather a way of thinking about how we might approach running our own bakeries differently.

Building upon the solid foundation of traditional Diversity and Inclusion strategies and structures, UMUC Europe is moving forward from a compliance model true competitive advantage with supplementations like "lunch-bucket D\&I" in the MBA program and "Speak Up!" in the broader university community, both of which seek to engrain inclusive behaviors into our habitual daily work of developing the next generation of inclusive leaders, professionals, and scholars.

\section{Conflicts of Interest}

The authors declare no conflicts of interest regarding the publication of this paper.

\section{References}

[1] Barney, J. (1991) Firm Resources and Sustained Competitive Advantage. Journal of Management, 17, 99-120. https://doi.org/10.1177/014920639101700108

[2] Robbins, S.P. and Judge, T.A. (2018) Essentials of Organizational Behavior. 14th Edition, Pearson Education, Inc., London.

[3] Tienda, M. (2013) Diversity $\neq$ Inclusion: Promoting Integration in Higher Education. Educational Researcher, 42, 467-475. http://journals.sagepub.com/ 
https://doi.org/10.3102/0013189X13516164

[4] Janis, I.L. (1982) Groupthink: Psychological Studies of Policy Decisions and Fiascoes. 2nd Edition, Cengage Learning, Boston, MA.

[5] Kowarski, I. (2017) U.S. News Data: A Portrait of the Typical MBA Student. U.S. News and World Report.

https://www.usnews.com/education/best-graduate-schools/top-business-schools/art icles/2017-03-14/us-news-data-a-portrait-of-the-typical-mba-student

[6] Hunt, V., Prince, S., Dixon-Fyle, S. and Yee, L. (2018) Delivering through Diversity. McKinsey \& Company, New York, NY.

https://www.mckinsey.com/business-functions/organization/our-insights/deliverin g-through-diversity

[7] Sahay, P. (2014) Design Thinking in Talent Acquisition: A Practitioner's Perspective. Strategic HR Review, 13, 170-180. https://doi.org/10.1108/SHR-04-2014-0027

[8] USM 2018 Strategic Plan (2018) The USM through 2020: A Renewed Vision for Powering Maryland Forward. https://www.usmd.edu/10yrplan/2018revision/

[9] Klein, G. (2017) From Strength to Strength: Building on 70 Years of Innovation. UMUC Achiever Magazine Spring 2017, 10-18.

https://issuu.com/umucachiever/docs/achiever_magazine_spring2017 